\title{
Synthesis and photoluminescence characterization of dendrimer- encapsulated CdS quantum dots
}

\author{
AUTHOR(S): \\ Yamamoto, Daigo; Koshiyama, Tomohiro; \\ Watanabe, Satoshi; Miyahara, Minoru T.
}

\section{CITATION:}

Yamamoto, Daigo ... [et al]. Synthesis and photoluminescence characterization of dendrimer-encapsulated CdS quantum dots. Colloids and Surfaces A: Physicochemical and Engineering Aspects 2012, 411: 12-17

\section{ISSUE DATE:}

2012-10-05

URL:

http://hdl.handle.net/2433/160098

\section{RIGHT:}

(c) 2012 Elsevier B.V.; この論文は出版社版でありません。引用の際には 出版社版をご確認ご利用ください。; This is not the published version. Please cite only the published version. 
Synthesis and Photoluminescence Characterization of Dendrimer-Encapsulated CdS

\section{Quantum Dots}

Daigo Yamamoto, Tomohiro Koshiyama, Satoshi Watanabe, and Minoru T. Miyahara*

Department of Chemical Engineering, Kyoto University, Katsura, Nishikyo, Kyoto 615-8510, Japan

miyahara@cheme.kyoto-u.ac.jp

Tel:+81-75-383-2662

Fax:+81-75-383-2652

* Corresponding author 


\section{Abstract}

We synthesized CdS quantum dots (QDs) encapsulated within $n$ th-generation hydroxyl-terminated poly(amidoamine) (PAMAM) dendrimers $(\mathrm{G} n-\mathrm{OH})$ by coordination of $\mathrm{Cd}^{2+}$ ions and subsequent reaction with $\mathrm{Na}_{2} \mathrm{~S}$. We systematically examined the effects of $\mathrm{Cd}^{2+}$ ion/dendrimer ratio $(x)$, generations of dendrimers, and temperatures on the resultant CdS QDs to elucidate the formation mechanism and to optimize the conditions for the encapsulation of QDs. The resultant QDs were analyzed by UV-vis spectroscopy, photoluminescence spectra spectroscopy, and transmission electron microscopy (TEM). Through a detailed analysis, we concluded that the first requisite for stable dispersions of $\mathrm{CdS}$ QDs with $\mathrm{G} n-\mathrm{OH}$ is to set $x$ to be less than $2^{n}$ because a $\mathrm{Cd}^{2+}$ ion is supposed to bind to two adjacent coordination sites of $2^{n+1}$ outermost tertiary amines of a $\mathrm{G} n-\mathrm{OH}$ dendrimer. Further, we clarified that higher-generation dendrimers can confine smaller QDs because of denser surfaces. Finally a lower temperature is found to promote the coordination of $\mathrm{Cd}^{2+}$ ions with dendrimers, and accordingly suppress the nucleation outside the dendrimers which produces larger QDs. 


\section{Introduction}

Semiconductor nanoparticles ranging from one to tens of nanometers in diameter, also known as quantum dots (QDs), exhibit unique size-tunable optical and electronic properties owing to the quantum size effect [1], unlike traditional fluorochromes [2] and fluorescent proteins [3]. QDs are of great interest for various applications, e.g., in optical devices, quantum information processing, and biotechnology[4-9]. CdS is one of the most researched semiconductor materials because bulk CdS has a band gap of $2.53 \mathrm{eV}$, which lies in the visible wavelength region. Many research groups have attempted to synthesize CdS QDs by various methods [10] since the successful preparation by Brus et al. in the early 1980s [11]. The synthetic methods should meet the following three requirements to fully exhibit the properties of the QDs. First, suspensions are preferred over aerosols or solid sols for better handling. Synthesizing QD suspensions is a popular topic and has been realized using various solvents over the last two decades. Second, the QDs should be strictly size-controlled and monodispersed. A size difference of a few angstroms can lead to a drastic change in their properties [12]. Third, the surfaces of the QDs should be modified to have varied functionality, which includes hydrophilicity, low-toxicity, and electric charge. However, a synthetic method that completely satisfies the three requirements has not yet been developed.

A dendrimer, which is a spherical hyperbranched polymer, is a possible candidate for use in

QD synthesis. The structure of a dendrimer is such that it grows in radial directions from a core 
with branches (the number of repeated branching cycles is called its "generation") and is terminated by a surface functional group [13]. Dendrimers are commonly represented as $\mathrm{G} n-\mathrm{X}$ according to their generation ( $n$th generation) and surface functional group $(X)$, both of which can be tuned. Poly(amidoamine) (PAMAM) dendrimers with an ethylenediamine core can serve as templates of metal nanoparticles. Crooks et al. and Balogh and Tomalia independently succeeded in encapsulating monodispersed $\mathrm{Cu}$ nanoparticles in PAMAM dendrimers [14, 15]. Since then, various types of metal nanoparticles have been prepared by encapsulation [16]. Nanoparticles encapsulated within PAMAM dendrimers can be synthesized by the incorporation of metal ions into dendrimers by coordinate bond formations with tertiary amine groups that are present at branching sites of the dendrimers, and by the subsequent particle formation with reductants such as $\mathrm{NaBH}_{4}$. The main advantage of this method is that resultant nanoparticles are monodispersed with controllable particle size.

This encapsulation method can be used for the synthesis of CdS QDs by using sulfides such as $\mathrm{Na}_{2} \mathrm{~S}$ instead of reductants in the particle formation process after the coordination of $\mathrm{Cd}^{2+}$ ions with dendrimers. Several research groups have prepared CdS QDs encapsulated within PAMAM dendrimers, and most of them have used amine-terminated dendrimers $\left(\mathrm{G} n-\mathrm{NH}_{2}\right)$ in their preparation [17-22]. However, a major limitation of this method is that the resultant CdS QDs are less stable than other dendrimer-encapsulated metal nanoparticles [20], which can be because $\mathrm{Cd}^{2+}$ 
ions bound to terminal primary amine ligands cause nucleation outside the dendrimers. For the synthesis of dendrimer-encapsulated Pt nanoparticles, hydroxyl-terminated dendrimers $(\mathrm{G} n-\mathrm{OH})$ are preferred over $\mathrm{G} n-\mathrm{NH}_{2}$ dendrimers because $\mathrm{Pt}^{2+}$ ions do not have a specific interaction with hydroxyl groups, and they can be transferred inside the dendrimers through the dendrimer surface. Moreover, we have demonstrated that a high coordination ratio of $\mathrm{Pt}^{2+}$ ions, which is defined as the ratio of metal ions coordinated with dendrimers to the total amount of metal ions, results in stable dendrimer-encapsulated $\mathrm{Pt}$ nanoparticles, whereas a low coordination ratio of $\mathrm{Pt}^{2+}$ ions produces particles outside the dendrimers [23]. Thus, the main reason for the aggregation of CdS QDs may be attributed to insufficient $\mathrm{Cd}^{2+}$ coordination. Some research groups have also synthesized dendrimer-encapsulated CdS QDs by using Gn-OH dendrimers [24-26]. However, the relationship between the $\mathrm{Cd}^{2+}$ coordination and the resultant $\mathrm{CdS}$ nanoparticles has not yet been completely understood because the coordination cannot be quantified by using UV-vis measurement. The spectra of the $\mathrm{Cd}^{2+}$ ions remained unchanged during coordination, unlike other metal ions [27]. This resulted in a difficulty in elucidating the $\mathrm{Cd}^{2+}$ coordination mechanism.

Recently, Bard et al. succeeded in quantifying the $\mathrm{Cd}^{2+}$ coordination with cyclic voltammetry [28]. They demonstrated that the $\mathrm{Cd}^{2+}$ coordination with $\mathrm{G} 2-\mathrm{OH}$ in water was accomplished in $30 \mathrm{~min}$, which is much shorter than several days for $\mathrm{Pt}^{2+}, \mathrm{Ru}^{3+}$, or $\mathrm{Ir}^{3+}$ ions [29-31]. This rapid $\mathrm{Cd}^{2+}$ coordination possibly results from a fast $\mathrm{H}_{2} \mathrm{O}$-ligand-exchange (aquation) rate 
because we have observed in our previous study that a slower aquation rate of metal ions, such as $\mathrm{Pt}^{2+}$ ions, results in a longer coordination period and vice versa [32]. This is why we investigated the dynamics of the coordination process in $\mathrm{Pt}^{2+}$ ions in that study. On the other hand, the key factor for coordination of $\mathrm{Cd}^{2+}$ ions would be thermodynamic equilibrium rather than kinetics because $\mathrm{Cd}^{2+}$ ions are predicted to have a lower coordination ratio than that of the solution using $\mathrm{Pt}^{2+}$ ions. We calculated the coordination ratio of a $1 \mathrm{mM}\left[\mathrm{G} 2-\mathrm{OH}+4 \mathrm{Cd}^{2+}\right]$ solution to be $70 \%$ at equilibrium by using the coordination equilibrium constants obtained by Bard et al. (refer to Supporting Information for calculation of the coordination ratio of a solution containing $\mathrm{Cd}^{2+}$ ions at equilibrium) [28]. Thus, enhancing the coordination ratio at equilibrium is our strategy to produce stable CdS QDs encapsulated within dendrimers without aggregations.

In the present study, we systematically examined the effects of the $\mathrm{Cd}^{2+}$ ion/dendrimer ratio $(x)$, generations of dendrimers, and temperatures - all of which affect the coordination ratio at equilibrium - on the resultant CdS QDs encapsulated within hydroxyl-terminated PAMAM dendrimers $(\mathrm{G} n-\mathrm{OH})$; our aim was to elucidate the formation mechanism of dendrimer-encapsulated CdS QDs and to determine the optimal conditions required for their encapsulation.

\section{Experimental Section}

\section{1. Chemicals}


The chemicals used in this study, which were $n$ th-generation hydroxyl-terminated PAMAM dendrimers ( $\mathrm{G} n-\mathrm{OH}$ in methanol solution, $n=4,6$, and 7), sodium polyphosphate (SPP) $\left[\left(\mathrm{NaPO}_{3}\right)_{6}\right.$, $96 \%]$, cadmium nitrate tetrahydrate $\left[\mathrm{Cd}\left(\mathrm{NO}_{3}\right)_{2} \cdot 4 \mathrm{H}_{2} \mathrm{O}, 99.999 \%\right]$, and sodium sulfide $\left(\mathrm{Na}_{2} \mathrm{~S}\right)$, were purchased from Aldrich Chemical Co. Methanol (99.8\%, Kishida Chemical Corp.) was used as solvent to prepare the dendrimer-encapsulated CdS QD suspensions. A control experiment was carried out using deionized (DI) water (18 M $\Omega \mathrm{cm}$, Millipore) as solvent to prepare SPP-protected CdS QD suspensions [21, 33]. All chemicals were used without further purification.

\subsection{Preparation of CdS QDs.}

$\mathrm{G} n-\mathrm{OH}$ solutions $(500 \mu \mathrm{M})$ were prepared first by being diluted with methanol, and the resulting solution was then mixed with a $\mathrm{Cd}\left(\mathrm{NO}_{3}\right)_{2}$ solution to obtain $\left[\mathrm{G} n-\mathrm{OH}+x \mathrm{Cd}^{2+}\right]$ solutions $(x=5,20,50,100,200$, or 400$)$. The concentration of $\mathrm{Cd}^{2+}$ ions was adjusted to $526 \mu \mathrm{M}$. The solutions were vigorously stirred for a few minutes and aged for $1 \mathrm{~h}$ at room temperature and $50{ }^{\circ} \mathrm{C}$, or for 1 day at $4{ }^{\circ} \mathrm{C},-18{ }^{\circ} \mathrm{C}$, and $-78^{\circ} \mathrm{C}$ to achieve equilibrium in $\mathrm{Cd}^{2+}$-tertiary amine coordination. Next, $0.25 \mathrm{ml}$ of $\mathrm{Na}_{2} \mathrm{~S}$ solution $(10 \mathrm{mM})$ was added to $4.75 \mathrm{ml}$ of $\left[\mathrm{G} n-\mathrm{OH}+x \mathrm{Cd}^{2+}\right]$ solution. In our experiments, the concentration of both Cd and S in the CdS QD suspensions was set to be $500 \mu \mathrm{M}$, whereas the concentration of $\mathrm{G} n-\mathrm{OH}$ varied with $x(500 / x \mu \mathrm{M})$.

SPP-protected CdS QDs were prepared by a procedure similar to the above mentioned one, except that SPP replaced Gn-OH as a protective agent and DI water replaced methanol as solvent. 
The concentration of SPP was set to be $500 \mu \mathrm{M}$.

\section{3. Instruments and Analysis.}

UV-vis absorbance spectra of the resultant CdS QD suspensions were measured with a spectrophotometer (UV-1700, Shimadzu) by using quartz cells (path length: $10 \mathrm{~mm}$ ). Room-temperature photoluminescence (PL) spectra were obtained using a spectrofluorometer (FP-6500, JASCO Corp.) and fluorometer cells (path length: $10 \mathrm{~mm}$ ). The extinction wavelength $\left(\lambda_{\mathrm{ex}}\right)$ was set to be $374 \mathrm{~nm}$ for all samples, which is around the wavelength of maximum absorbance. The resultant CdS particles were observed by transmission electron microscopy (TEM) (JEM-1010, JEOL). Samples for TEM observation were prepared by placing a drop of the CdS QD suspensions on a carbon-coated copper grid (Okenshoji Co.), which was then dried in vacuum. Freshly prepared samples were used for all measurements and observations.

\section{Results and Discussion}

\section{1. Effects of $x$ on resultant CdS QDs.}

The G6-OH CdS QD suspensions were colorless ( $x=5,20,50$, and 100) or faint yellow ( $x=200$ and 400). However, SPP-protected CdS QD suspensions were yellow, which reflects the color of bulk CdS. This demonstrates that smaller particles were produced in the case of dendrimers than those with SPP. Fig. 1 shows the UV-vis absorbance spectra of G6-OH CdS QDs 
for various values of $x(x=5,20,50,100,200$, and 400) prepared at room temperature. The experimental diameters of resultant CdS nanocrystals were determined from the absorbance peak by using the empirical equation proposed by Peng et al. [34], which are summarized in the third column of Table 1 . Theoretical values of these average sizes were also calculated by assuming spherical-shape nanocrystals that consisted of $x$ atoms of $\mathrm{Cd}$ and $\mathrm{S}$, respectively, by using the approximation method proposed by Lippens and Lannoo [35]. The experimental diameters of the $\mathrm{CdS}$ nanocrystals decrease as $x$ decreases, and are slightly larger than the theoretical diameters as shown in Table 1. One of the main reasons for the difference between experimental and theoretical diameters is that a CdS particle confined in the limited space in a dendrimer molecule would not be spherical in shape; it would be instead subspherical and resemble a hemisphere, which is similar to other metal nanoparticles encapsulated within dendrimers [36, 37]. Moreover, uncoordinated $\mathrm{Cd}^{2+}$ ions cause nucleation and particle growth outside dendrimers, which results in particles with larger diameters because of coalescence. Fig. 2 shows PL spectra of the CdS QD suspensions for various values of $x$. These spectra were normalized by setting the peak intensity to be 1.0. The PL peak shifted toward shorter wavelengths (blue shift) for smaller values of $x$, which is similar to the UV-vis absorbance spectra in Fig. 1, because smaller CdS QDs have wider band gaps. Moreover, the 


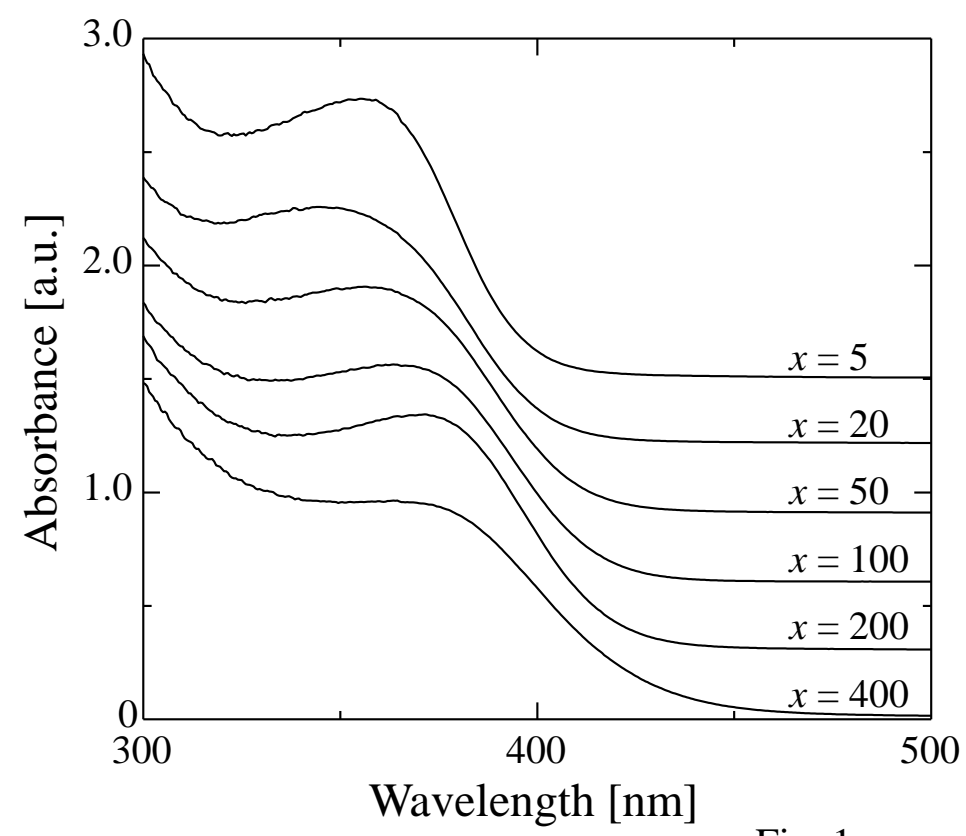

Fig. 1.

\begin{tabular}{rccc}
\hline$x$ & Absorbance peak $[\mathrm{nm}]$ & Experimental diameter $[\mathrm{nm}]^{31}$ & ${\text { Theoretical diameter }[\mathrm{nm}]^{32}}^{32}$ \\
5 & 355 & 2.2 & 0.6 \\
20 & 344 & 2.0 & 1.0 \\
50 & 356 & 2.2 & 1.3 \\
100 & 364 & 2.4 & 1.7 \\
200 & 372 & 2.6 & 2.1 \\
400 & 375 & 2.7 & 2.7 \\
\hline
\end{tabular}

Table 1.

dendrimer-protected QD suspensions have a peak at shorter wavelengths and a significantly higher PL intensity than SPP-protected QD suspensions, which is shown in Fig. S1 in Supporting Information. The shape of PL spectra is multimodal and is attributed to S-related defects (at shorter wavelengths) and Cd-related defects (at longer wavelengths) [38]. The subspherical shape of dendrimer-encapsulated CdS QDs may also lead to multimodal-shaped PL spectra, in contrast to CdS QDs synthesized by other methods [39-41]. According to the PL spectra, the suspensions exhibited different photoluminescence colors varying from blue to orange when illuminated with a 


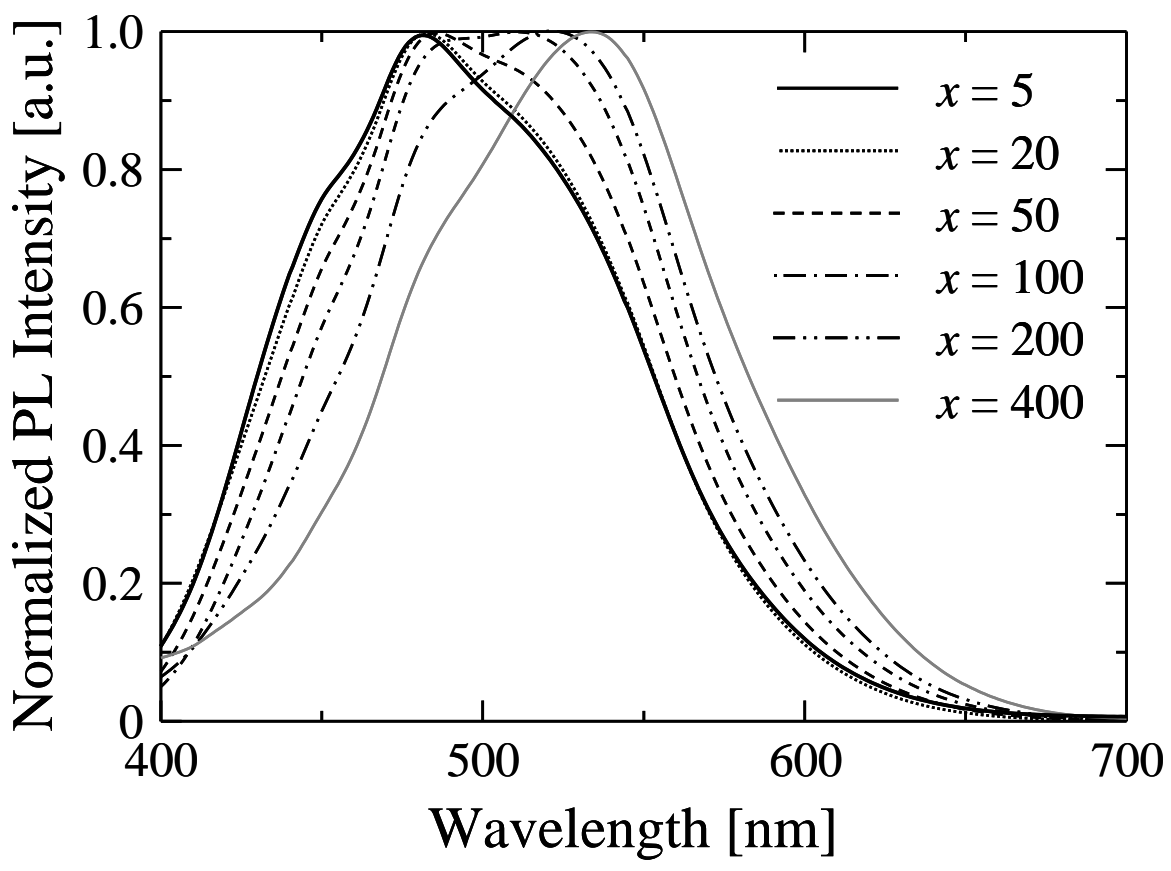

Fig. 2.

UV lamp $\quad\left(\lambda_{\mathrm{ex}}=356 \mathrm{~nm}\right)$, whereas a SPP-protected CdS QD suspension turned red (refer to Supporting Information, Fig. S2).

We observed the resultant CdS QDs by TEM to examine the stability in the suspensions (Fig. 3). Note that TEM images can be used to judge the dispersion state (dispersed or aggregated), but are not clear enough to discriminate size and shape of individual particles because of the high transmission nature of the CdS particles. In contrast to well-dispersed particles with $x=20$ and 50 (Fig. 3a, b), those with $x=200$ were highly aggregated (Fig. 3c). As in the case of Pt nanoparticles where aggregates are typically observed under a low coordination ratio condition [23], the aggregate formation with $x=200$ would be attributed to the low coordination ratio of $\mathrm{Cd}^{2+}$ ions. 
According to our calculations, coordination ratios for $x=20$ and 200 are estimated to be $93 \%$ and $19 \%$ respectively

(Fig.

S3).

When

the

\section{a}

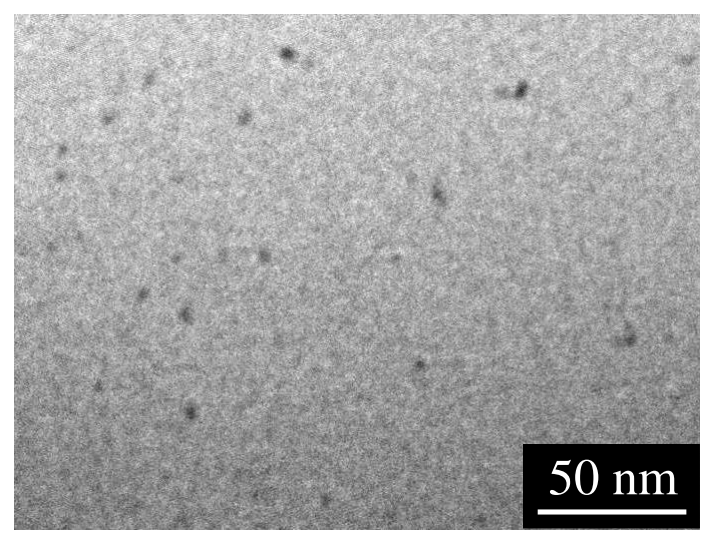

C

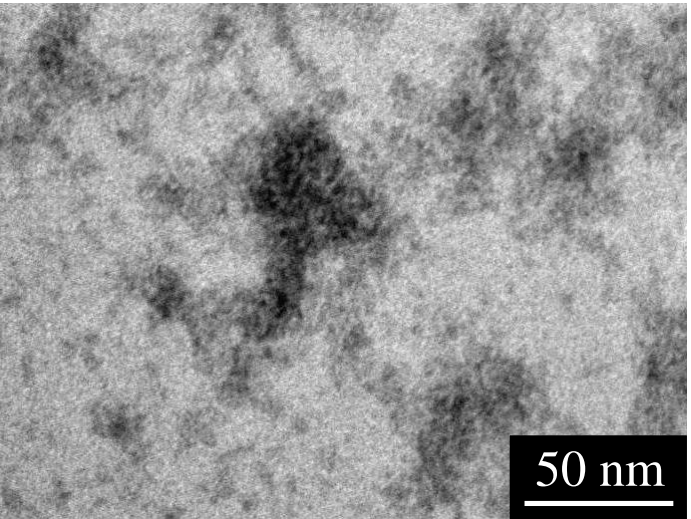

$\mathrm{b}$

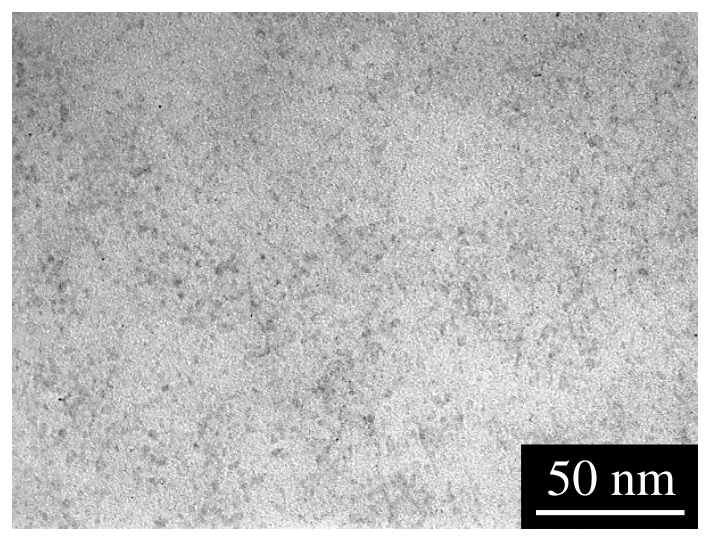

Fig. 3.

coordination ratio is low, nucleation and particle growth occur outside the dendrimers because a number of $\mathrm{Cd}^{2+}$ ions remain uncoordinated. Particles not encapsulated in dendrimers aggregate and form subsequent precipitates. In fact, precipitates were observed after a few days for $x=100,200$, and 400, whereas no precipitates appeared in several weeks for $x=5,20$, and 50. The boundary for the CdS QDs encapsulation thus appears to exist between $x=50$ and 100. This result agrees with 
those reported previously that the coordination behavior of $\mathrm{Cd}^{2+}$ ions with dendrimers is similar to that of $\mathrm{Cu}^{2+}$ ions, each of which binds to two adjacent coordination sites of the outermost tertiary amines [28, 42]. The maximum coordination number of $\mathrm{Cd}^{2+}$ ions within a G6-OH dendrimer would thus be 64 because a G6-OH molecule contains 128 outermost amine sites at the edge. It is thought that stable dispersions of CdS QDs encapsulated within $\mathrm{G} n-\mathrm{OH}$ dendrimers are produced by setting the ratio $x$ to be less than $2^{n}$.

Another noticeable observation in Table 1 is that contrary to our expectation, the blue shift of an absorbance peak is not observed for $x=5$, and the average size $(d=2.2 \mathrm{~nm})$ is larger than that in the case of $x=20(d=2.0 \mathrm{~nm})$. This can be attributed to coalescence of CdS clusters outside the dendrimers because the $\mathrm{CdS}$ clusters formed in the dendrimers are so small that they can pass through the periphery of dendrimers. Because dendrimers form flocs [43], coalescence occurs more easily inside flocs, which in turn protect resultant nanoparticles for $x=5$. In fact, precipitations were not observed for $x=5$, unlike in the case of $x=400$. Because it was observed that surface density of dendrimers increases with increasing generation [44], we prepared CdS QD suspensions for $x=20$ with PAMAM dendrimers having various generations $(\mathrm{G} n-\mathrm{OH} ; n=4,6$, and 7$)$ at room temperature (Fig. 4) to examine the effect of the surface density of the dendrimers on the size of resultant CdS QDs. As shown in Fig. 4, the use of a higher-generation dendrimer results in a PL peak at shorter wavelengths, which indicates the formation of smaller QDs. Precipitates were 
observed only in G4-OH dendrimers. These results suggest that the size of the smallest QDs that can be encapsulated within dendrimers depends on the generation of the dendrimers. In other words, higher-generation dendrimers having denser surfaces can confine smaller dendrimer-encapsulated CdS QDs.

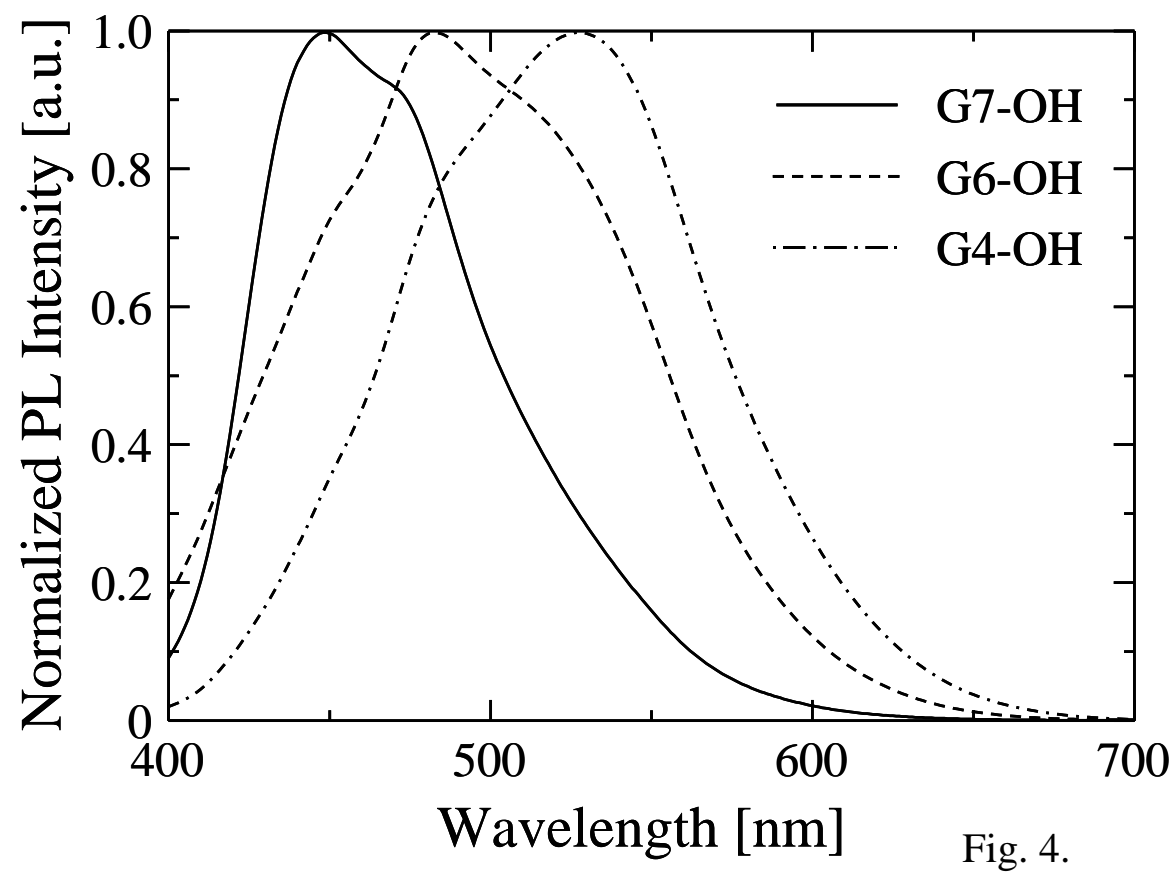

\section{2. Effect of temperature on CdS QDs.}

In the experiments shown above, the aging period was set to be $1 \mathrm{~h}$ to achieve coordination equilibrium. We confirmed that both the UV-vis absorbance spectra and the PL spectra remained unchanged when the duration of coordination was set to be 1 min or 1 day, indicating immediate coordination of $\mathrm{Cd}^{2+}$ ions. However, according to our calculation of the coordination ratio of a $\left[\mathrm{G} 6-\mathrm{OH}+x \mathrm{Cd}^{2+}\right]\left(\left[\mathrm{Cd}^{2+}\right]=500 \mu \mathrm{M}\right)$ solution, the equilibrium coordination ratio with G6-OH 
would not reach $100 \%$ at room temperature, even at $x<64$ (Fig. S3). Nucleation also appears to occur outside the dendrimers for $x=50$ because the coordination ratio at room temperature is estimated to be only $63 \%$ (Fig. S3).

Bryszewska et al. have demonstrated that the coordination process of $\mathrm{Cd}^{2+}$ ions is exothermic [45]. Thus, coordination equilibrium shifts towards the $\mathrm{Cd}^{2+}$-tertiary amine complexes as temperature decreases. Fig. 5 shows the PL spectra of G6-OH CdS QDs for $x=50$ prepared at various temperatures $\left(50{ }^{\circ} \mathrm{C}\right.$, room temperature, $4{ }^{\circ} \mathrm{C},-18{ }^{\circ} \mathrm{C}$, and $\left.-78^{\circ} \mathrm{C}\right)$. The peak shifts toward shorter wavelengths with a decrease in the temperature, which indicates that lower temperatures yield smaller CdS QDs. Conversely, in the case of SPP-protected CdS QDs, the PL peak showed no shift at $50{ }^{\circ} \mathrm{C}$, at room temperature, and at $4{ }^{\circ} \mathrm{C}$ (see Fig. S4; no data were obtained at $-18{ }^{\circ} \mathrm{C}$ or $-78{ }^{\circ} \mathrm{C}$ because water was used as solvent), suggesting that the temperature difference had a negligible effect on the nucleation process. Thus, the results demonstrate that blue shift with dendrimers at lower temperatures cannot be attributed to nucleation and particle growth; instead, it can be attributed to a higher coordination ratio of $\mathrm{Cd}^{2+}$ ions. A higher coordination ratio at lower temperatures led to a decrease in the number of uncoordinated $\mathrm{Cd}^{2+}$ ions, which caused nucleation outside the dendrimers. Therefore, we conclude that lower temperatures are preferred for encapsulation of CdS QDs. However, it should be noted that lowering the temperature is effective only for metal ions that have high coordination rate, such as $\mathrm{Cd}^{2+}$ ions, because the lower 
temperature slows the coordination rate. For instance, we have demonstrated that $\mathrm{Pt}^{2+}$ coordination ratio at $4{ }^{\circ} \mathrm{C}$ is only $50 \%$ even after 10 days [23].

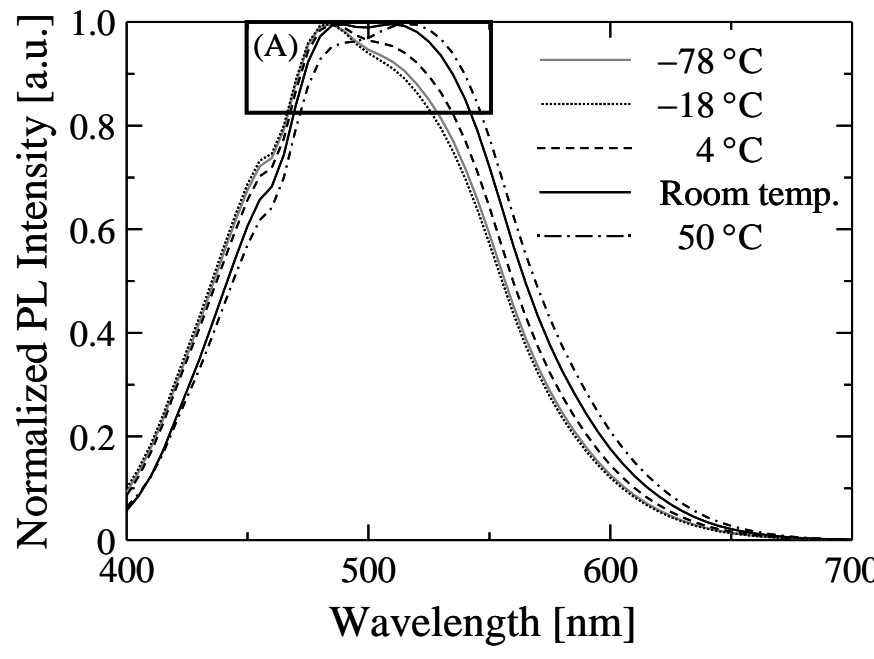

Wavelength [nm]

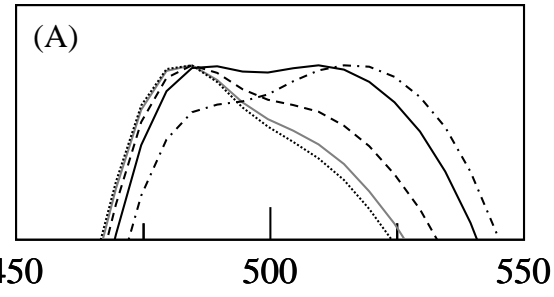

Fig. 5.

\section{3. Formation Mechanism.}

From these results, we propose a mechanism of encapsulation of CdS QDs within $\mathrm{G} n-\mathrm{OH}$ dendrimers (Fig. 6). At a high value of $x\left(x>2^{n} ; x\right.$ is greater than 64 in the case of G6-OH), most of the nucleation occurs outside the dendrimers and the nanoparticles are not encapsulated but are surrounded by some dendrimer molecules, although precipitates are observed after a few days. At intermediate values of $x\left(x \sim 2^{n}\right)$, which means that the value of $x$ is slightly less than $2^{n}$, nucleation occurs not only in the dendrimers but also outside them because the coordination ratio at equilibrium is low at room temperature. A lower temperature is preferred to promote the coordination of $\mathrm{Cd}^{2+}$ ions and it leads to the decrease in nucleation outside the dendrimers. At low 
values of $x\left(x<2^{n}\right)$, resultant nanoclusters are so small that they cannot be encapsulated within dendrimers. They tend to coalesce into a larger particle. Higher-generation dendrimers are better candidates for templates as they would prevent the clusters from coalescing owing to denser surfaces. Thus, the use of higher-generation dendrimers at lower temperatures is a requisite for the preparation of stable CdS QDs encapsulated within dendrimers.
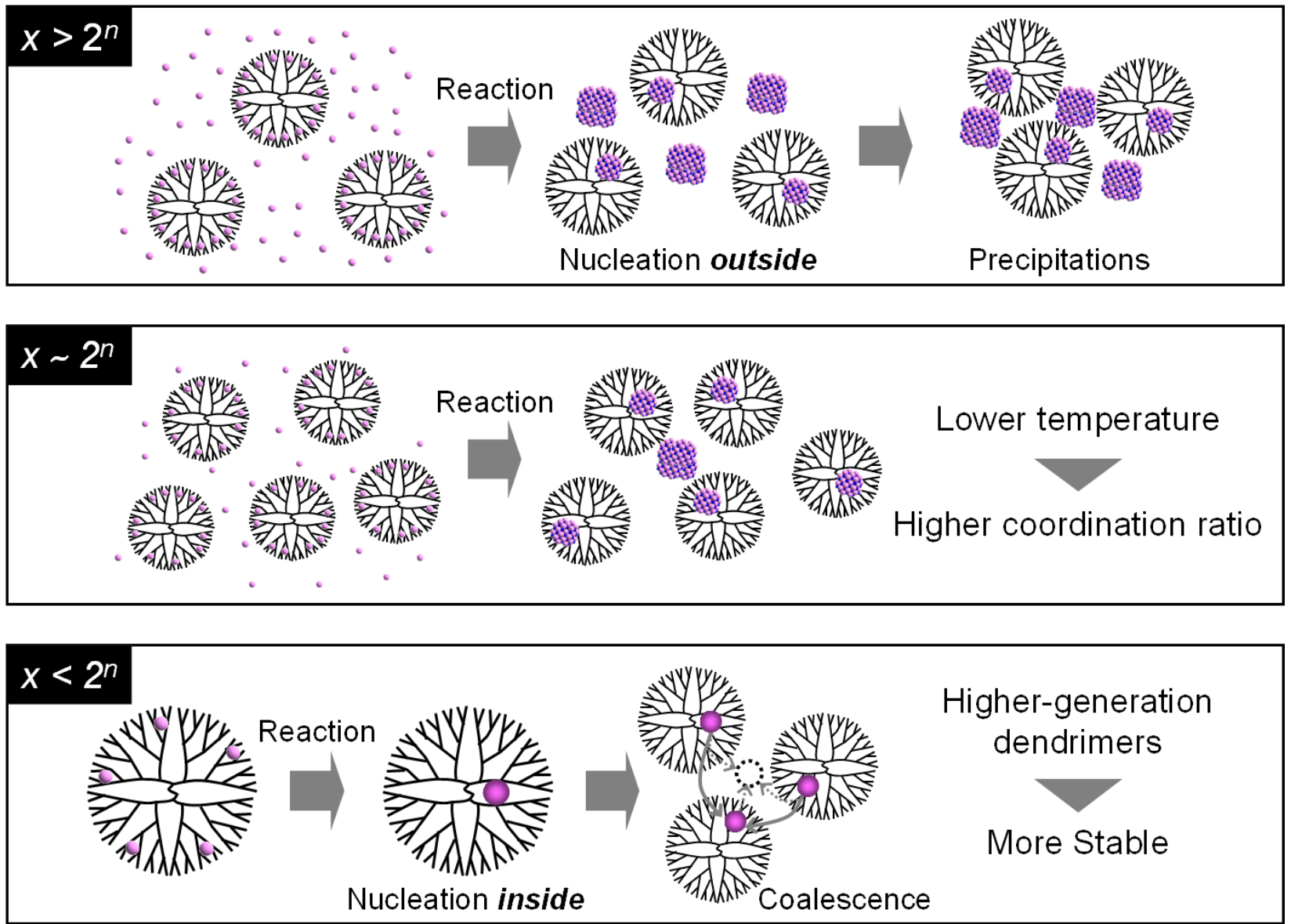

Fig. 6.

\section{Conclusions}

We synthesized CdS QDs by using hydroxyl-terminated PAMAM dendrimers as templates 
and investigated the effects of $\mathrm{Cd}^{2+}$ ion/dendrimer ratio $(x)$, dendrimer generations, and temperatures on the resultant CdS QDs. Through a detailed analysis, we found that setting $x$ to be less than $2^{n}$ enables most of the nucleation to occur inside the dendrimers, which leads to stable dendrimer-encapsulated CdS QDs. We also demonstrated that higher-generation dendrimers can confine smaller QDs because they have denser surfaces. Further, lowering the temperature is a simple and effective approach to enhance the coordination ratio at equilibrium and to decrease nucleation outside the dendrimers, although it slows the coordination rate. In this manner, enhancing the coordination ratio of $\mathrm{Cd}^{2+}$ ion with dendrimers is the key for synthesizing stable dendrimer-encapsulated CdS QD suspensions, and is possible by changing $x$, generations of dendrimers, and temperatures to control particle sizes and photoluminescence colors.

\section{Acknowledgement}

This work was supported by a Grant-in-Aid for Scientific Research (B), the Global Center of Excellence (G-COE) program, and the Core-to-Core (CTC) Program from the Japan Society for the Promotion of Science (JSPS). We also thank Prof. Yasushige Mori and Mr. Yuki Hirota (Doshisha University) for assistance with the PL measurement.

Supporting Information Available: The details of the calculation of the coordination ratio of $\mathrm{Cd}^{2+}$ ions at equilibrium are described in Supporting Information. Comparison of PL intensity between 
CdS QDs with G6-OH PAMAM dendrimers and those with the SPP-protected dendrimers, PL images of CdS QDs taken with a digital camera (Canon) within G6-OH dendrimers for various values of $x$ illuminated with a UV lamp $\left(\lambda_{\mathrm{ex}}=356 \mathrm{~nm}\right)$ in a dark room, coordination ratio of $\left[\mathrm{G6}-\mathrm{OH}+x \mathrm{Cd}^{2+}\right]$ solutions, and PL spectra of SPP-protected CdS QDs at various temperatures $\left(\lambda_{\mathrm{ex}}\right.$ $=374 \mathrm{~nm}$ ) are also available free of charge via the Internet at

\section{FIGURE CAPTIONS}

Fig. 1. UV-vis absorbance spectra of G6-OH CdS QDs for various values of $x$ at room temperature.

Methanol was used to obtain the background spectrum.

Table 1. Average sizes obtained experimentally and the theoretical sizes of CdS QDs for various values of $x$. The average sizes were calculated from Fig. 1 using the empirical equation proposed by Peng et al. [34] and the theoretical sizes were calculated by the approximation method proposed by Lippens and Lannoo [35].

Fig. 2. PL spectra of G6-OH CdS QDs for various values of $x$ at room temperature. PL spectra were measured with the excitation wavelength at $374 \mathrm{~nm}$.

Fig. 3. TEM images of resultant CdS particles with G6-OH dendrimers for (a) $x=20$, (b) 50, and (c) 400 .

Fig. 4. PL spectra of CdS QDs with PAMAM dendrimers having various generations for $x=20$ ( $\lambda_{\mathrm{ex}}$ 
$=374 \mathrm{~nm})$.

Fig. 5. PL spectra of G6-OH CdS QDs for $x=50$ at various temperatures $\left(\lambda_{\mathrm{ex}}=374 \mathrm{~nm}\right)$.

Fig. 6. Synthetic mechanism for CdS QDs encapsulated within $\mathrm{G} n-\mathrm{OH}$ dendrimers.

\section{References}

[1] L.E. Brus, Electron Electron and Electron-Hole Interactions in Small Semiconductor Crystallites

- the Size Dependence of the Lowest Excited Electronic State, J. Chem. Phys., 80 (1984) 4403-4409.

[2] I. Hilwig, A. Gropp, Staining of Constitutive Heterochromatin in Mammalian Chromosomes with a New Fluorochrome, Exp. Cell Res., 75 (1972) 122-126.

[3] M. Chalfie, Y. Tu, G. Euskirchen, W.W. Ward, D.C. Prasher, Green Fluorescent Protein as a Marker for Gene-Expression, Science, 263 (1994) 802-805.

[4] D.P. DiVincenzo, D. Loss, Quantum computers and quantum coherence, J. Magn. Magn. Mater., 200 (1999) 202-218.

[5] V.I. Klimov, A.A. Mikhailovsky, S. Xu, A. Malko, J.A. Hollingsworth, C.A. Leatherdale, H.J. Eisler, M.G. Bawendi, Optical gain and stimulated emission in nanocrystal quantum dots, Science, 290 (2000) 314-317. 
[6] I.L. Medintz, H.T. Uyeda, E.R. Goldman, H. Mattoussi, Quantum dot bioconjugates for imaging, labelling and sensing, Nat. Mater., 4 (2005) 435-446.

[7] X. Yan, Y. Cui, W. Qi, Y. Su, Y. Yang, Q. He, J. Li, Self-assembly of peptide-based colloids containing lipophilic nanocrystals, Small, 4 (2008) 1687-1693.

[8] X. Yan, Y. Cui, Q. He, K. Wang, J. Li, Organogels Based on Self-Assembly of Diphenylalanine Peptide and Their Application To Immobilize Quantum Dots, Chem. Mater., 20 (2008) 1522-1526.

[9] D. Bardelang, M.B. Zaman, I.L. Moudrakovski, S. Pawsey, J.C. Margeson, D. Wang, X. Wu, J.A. Ripmeester, C.I. Ratcliffe, K. Yu, Interfacing Supramolecular Gels and Quantum Dots with Ultrasound: Smart Photoluminescent Dipeptide Gels, Adv. Mater., 20 (2008) 4517-4520.

[10] T. Trindade, P. O'Brien, N.L. Pickett, Nanocrystalline semiconductors: Synthesis, properties, and perspectives, Chem. Mater., 13 (2001) 3843-3858.

[11] R. Rossetti, J.L. Ellison, J.M. Gibson, L.E. Brus, Size Effects in the Excited Electronic States of Small Colloidal CdS Crystallites, J. Chem. Phys., 80 (1984) 4464-4469.

[12] H. Mattoussi, L.H. Radzilowski, B.O. Dabbousi, E.L. Thomas, M.G. Bawendi, M.F. Rubner, Electroluminescence from heterostructures of poly(phenylene vinylene) and inorganic CdSe nanocrystals, J. Appl. Phys., 83 (1998) 7965-7974.

[13] D.A. Tomalia, H. Baker, J. Dewald, M. Hall, G. Kallos, S. Martin, J. Roeck, J. Ryder, P. Smith, A new Class of Polymers - Starburst-Dendritic Macromolecules, Polym. J., 17 (1985) 117-132. 
[14] M.Q. Zhao, L. Sun, R.M. Crooks, Preparation of $\mathrm{Cu}$ nanoclusters within dendrimer templates, J. Am. Chem. Soc., 120 (1998) 4877-4878.

[15] L. Balogh, D.A. Tomalia, Poly(amidoamine) dendrimer-templated nanocomposites. 1. Synthesis of zerovalent copper nanoclusters, J. Am. Chem. Soc., 120 (1998) 7355-7356.

[16] R.W.J. Scott, O.M. Wilson, R.M. Crooks, Synthesis, characterization, and applications of dendrimer-encapsulated nanoparticles, J. Phys. Chem. B, 109 (2005) 692-704.

[17] S. Ghosh, S.C. Bhattacharya, A. Saha, Probing of ascorbic acid by CdS/dendrimer nanocomposites: a spectroscopic investigation, Anal. Bioanal. Chem., 397 (2010) 1573-1582.

[18] J. Yu-Juan, L. Yun-Jun, L. Guo-Ping, L. Jie, W. Yuan-Feng, Y. Rui-Qin, L. Wen-Ting, Application of photoluminescent CdS/PAMAM nanocomposites in fingerprint detection, Forensic Sci. Int., 179 (2008) 34-38.

[19] X.C. Wu, A.M. Bittner, K. Kern, Synthesis, photoluminescence, and adsorption of CdS/dendrimer nanocomposites, J. Phys. Chem. B, 109 (2005) 230-239.

[20] L.H. Hanus, K. Sooklal, C.J. Murphy, H.J. Ploehn, Aggregation kinetics of dendrimer-stabilized CdS nanoclusters, Langmuir, 16 (2000) 2621-2626.

[21] J.R. Lakowicz, I. Gryczynski, Z. Gryczynski, C.J. Murphy, Luminescence spectral properties of CdS nanoparticles, J. Phys. Chem. B, 103 (1999) 7613-7620.

[22] K. Sooklal, L.H. Hanus, H.J. Ploehn, C.J. Murphy, A blue-emitting CdS/dendrimer 
nanocomposite, Adv. Mater., 10 (1998) 1083-1087.

[23] D. Yamamoto, S. Watanabe, M.T. Miyahara, Coordination and Reduction Processes in the Synthesis of Dendrimer-Encapsulated Pt Nanoparticles, Langmuir, 26 (2009) 2339-2345.

[24] P. Zhang, T.K. Sham, The electronic and optical properties of dendrimer-capped CdS quantum dots: A UV-vis and x-ray spectroscopy study, Phys. Scr., T115 (2005) 1019-1021.

[25] P. Zhang, S.J. Naftel, T.K. Sham, Multichannel detection x-ray absorption near edge structures study on the structural characteristics of dendrimer-stabilized CdS quantum dots, J. Appl. Phys., 90 (2001) 2755-2759.

[26] B.I. Lemon, R.M. Crooks, Preparation and characterization of dendrimer-encapsulated CdS semiconductor quantum dots, J. Am. Chem. Soc., 122 (2000) 12886-12887.

[27] R.M. Crooks, M.Q. Zhao, L. Sun, V. Chechik, L.K. Yeung, Dendrimer-encapsulated metal nanoparticles: Synthesis, characterization, and applications to catalysis, Acc. Chem. Res., 34 (2001) 181-190.

[28] A.B. Nepomnyashchii, M.A. Alpuche-Aviles, S.L. Pan, D.P. Zhan, F.R.F. Fan, A.J. Bard, Cyclic voltammetry studies of $\mathrm{Cd} 2+$ and $\mathrm{Zn} 2+$ complexation with hydroxyl-terminated polyamidoamine generation 2 dendrimer at a mercury microelectrode, J. Electroanal. Chem., 621 (2008) 286-296.

[29] Y. Jesus, A. Vicente, G. Lafaye, P. Marecot, C.T. Williams, Synthesis and characterization of 
dendrimer-derived supported iridium catalysts, J. Phys. Chem. C, 112 (2008) 13837-13845.

[30] G. Lafaye, C.T. Williams, M.D. Amiridis, Synthesis and microscopic characterization of dendrimer-derived Ru/Al2O3 catalysts, Catal. Lett., 96 (2004) 43-47.

[31] M.Q. Zhao, R.M. Crooks, Dendrimer-encapsulated Pt nanoparticles: Synthesis, characterization, and applications to catalysis, Adv. Mater., 11 (1999) 217-220.

[32] D. Yamamoto, S. Watanabe, M.T. Miyahara, Modeling Pt(2+) Coordination Process within Poly(amidoamine) Dendrimers for Synthesis of Dendrimer-Encapsulated Pt Nanoparticles, Ind. Eng. Chem. Res., 50 (2011) 7332-7337.

[33] A. Fojtik, H. Weller, U. Koch, A. Henglein, Photo-Chemistry of Colloidal Metal Sulfides .8. Photo-Physics of Extremely Small CdS Particles - Q-State CdS and Magic Agglomeration Numbers, Ber. Bunsen-Ges. Phys. Chem. Chem. Phys., 88 (1984) 969-977.

[34] W.W. Yu, L.H. Qu, W.Z. Guo, X.G. Peng, Experimental determination of the extinction coefficient of CdTe, CdSe, and CdS nanocrystals, Chem. Mater., 15 (2003) 2854-2860.

[35] P.E. Lippens, M. Lannoo, Calculation of the Band-Gap for Small CdS and ZnS Crystallites, Phys. Rev. B, 39 (1989) 10935-10942.

[36] Y.L. Gu, H. Xie, J.X. Gao, D.X. Liu, C.T. Williams, C.J. Murphy, H.J. Ploehn, AFM characterization of dendrimer-stabilized platinum nanoparticles, Langmuir, 21 (2005) 3122-3131.

[37] M.Q. Zhao, R.M. Crooks, Homogeneous hydrogenation catalysis with monodisperse, 
dendrimer-encapsulated Pd and Pt nanoparticles, Angew. Chem. Int. Ed., 38 (1999) 364-366.

[38] Y. Wang, N. Herron, Photoluminescence and Relaxation dynamics of CdS Superclusters in Zeolites, J. Phys. Chem., 92 (1988) 4988-4994.

[39] B. Ludolph, M.A. Malik, P. O'Brien, N. Revaprasadu, Novel single molecule precursor routes for the direct synthesis of highly monodispersed quantum dots of cadmium or zinc sulfide or selenide, Chem. Commun., (1998) 1849-1850.

[40] J.R. Babcock, R.W. Zehner, L.R. Sita, A heterocumulene metathesis route to Cd[ESiMe3](2) and passivated $\mathrm{CdE}(\mathrm{E}=\mathrm{S}$ and Se) nanocrystals, Chem. Mater., 10 (1998) 2027-2029.

[41] N. Chestnoy, T.D. Harris, R. Hull, L.E. Brus, Luminescence and Photophysics of CdS Semiconductor Clusters - the Nature of the Emitting Electronic state, J. Phys. Chem., 90 (1986) 3393-3399.

[42] L. Zhou, D.H. Russell, M.Q. Zhao, R.M. Crooks, Characterization of poly(amidoamine) dendrimers and their complexes with $\mathrm{Cu} 2+$ by matrix-assisted laser desorption ionization mass spectrometry, Macromolecules, 34 (2001) 3567-3573.

[43] M.J. Jasmine, M. Kavitha, E. Prasad, Effect of solvent-controlled aggregation on the intrinsic emission properties of PAMAM dendrimers, J. Lumin., 129 (2009) 506-513.

[44] P.K. Maiti, T. Cagin, G.F. Wang, W.A. Goddard, Structure of PAMAM dendrimers: Generations 1 through 11, Macromolecules, 37 (2004) 6236-6254. 
[45] D. Shcharbin, J. Mazur, M. Szwedzka, M. Wasiak, B. Palecz, M. Przybyszewska, M. Zaborski,

M. Bryszewska, Interaction between PAMAM 4.5 dendrimer, cadmium and bovine serum albumin:

A study using equilibrium dialysis, isothermal titration calorimetry, zeta-potential and fluorescence,

Colloid Surf., B, 58 (2007) 286-289. 


\section{Supporting Information for:}

Synthesis and Photoluminescence Characterization of Dendrimer-Encapsulated CdS

\section{Quantum Dots}

Daigo Yamamoto, Tomohiro Koshiyama, Satoshi Watanabe, and Minoru T. Miyahara*

Department of Chemical Engineering, Kyoto University, Katsura, Nishikyo, Kyoto 615-8510, Japan

miyahara@cheme.kyoto-u.ac.jp

* Corresponding author 


\section{Calculation of $\mathrm{Cd}^{2+}$ coordination ratio at equilibrium.}

We calculated $\mathrm{Cd}^{2+}$ coordination ratio at equilibrium by using cumulative consecutive constants of $\mathrm{Cd}^{2+}-\mathrm{G} 2-\mathrm{OH}$ coordination determined by Bard et al. [1] The reactions of $\mathrm{Cd}^{2+}$ complexes with $\mathrm{G} 2-\mathrm{OH}$ at $25^{\circ} \mathrm{C}$ are expressed by the following equations:

$\mathrm{G} 2-\mathrm{OH}+\mathrm{Cd}^{2+} \stackrel{K_{1}}{\rightleftarrows} \mathrm{G} 2-\mathrm{OH}-\mathrm{Cd}^{2+}$

$\mathrm{G} 2-\mathrm{OH}+2 \mathrm{Cd}^{2+} \stackrel{K_{2}}{\rightleftarrows} \mathrm{G} 2-\mathrm{OH}-\left(\mathrm{Cd}^{2+}\right)_{2}$

$\mathrm{G} 2-\mathrm{OH}+3 \mathrm{Cd}^{2+} \stackrel{K_{3}}{\rightleftarrows} \mathrm{G} 2-\mathrm{OH}-\left(\mathrm{Cd}^{2+}\right)_{3}$

$\mathrm{G} 2-\mathrm{OH}+4 \mathrm{Cd}^{2+} \stackrel{K_{4}}{\rightleftarrows} \mathrm{G} 2-\mathrm{OH}-\left(\mathrm{Cd}^{2+}\right)_{4}$

$K_{1}=\frac{\left[\mathrm{G} 2-\mathrm{OH}-\mathrm{Cd}^{2+}\right]_{\mathrm{eq}}}{\left[\mathrm{Cd}^{2+}\right]_{\mathrm{eq}}[\mathrm{G} 2-\mathrm{OH}]_{\mathrm{eq}}}=1.3 \times 10^{5} \mathrm{M}^{-1}$

$K_{2}=\frac{\left[\mathrm{G} 2-\mathrm{OH}-\left(\mathrm{Cd}^{2+}\right)_{2}\right]_{\mathrm{eq}}}{\left[\mathrm{Cd}^{2+}\right]_{\mathrm{eq}}^{2}[\mathrm{G} 2-\mathrm{OH}]_{\mathrm{eq}}}=1.6 \times 10^{9} \mathrm{M}^{-2}$

$K_{3}=\frac{\left[\mathrm{G} 2-\mathrm{OH}-\left(\mathrm{Cd}^{2+}\right)_{3}\right]_{\mathrm{eq}}}{\left[\mathrm{Cd}^{2+}\right]_{\mathrm{eq}}^{3}[\mathrm{G} 2-\mathrm{OH}]_{\mathrm{eq}}}=3.3 \times 10^{12} \mathrm{M}^{-3}$

$K_{4}=\frac{\left[\mathrm{G} 2-\mathrm{OH}-\left(\mathrm{Cd}^{2+}\right)_{4}\right]_{\mathrm{eq}}}{\left[\mathrm{Cd}^{2+}\right]_{\mathrm{eq}}^{4}[\mathrm{G} 2-\mathrm{OH}]_{\mathrm{eq}}}=4.6 \times 10^{14} \mathrm{M}^{-4}$ 
where, $K_{i}(i=1-4)$ is the equilibrium constant, the square brackets [ ] represent the concentration, and the subscript eq denotes the equilibrium condition.

Material balances of $\mathrm{Cd}^{2+}$ and $\mathrm{G} 2-\mathrm{OH}$ are described as follows:

$$
\begin{aligned}
& {\left[\mathrm{Cd}^{2+}\right]_{\text {initial }}=\left[\mathrm{Cd}^{2+}\right]_{\mathrm{eq}}+\sum_{k=1}^{4} k \times\left[\mathrm{G} 2-\mathrm{OH}-\left(\mathrm{Cd}^{2+}\right)_{k}\right]_{\mathrm{eq}}} \\
& {[\mathrm{G} 2-\mathrm{OH}]_{\text {initial }}=[\mathrm{G} 2-\mathrm{OH}]_{\mathrm{eq}}+\sum_{k=1}^{4}\left[\mathrm{G} 2-\mathrm{OH}-\left(\mathrm{Cd}^{2+}\right)_{k}\right]_{\mathrm{eq}}}
\end{aligned}
$$

where, the subscript initial denotes the initial condition. We solved simultaneous equations (S5-10) using Newton-Raphson method.

The coordination ratio $\alpha$ at equilibrium is obtained by the following equation:

$$
\alpha=\frac{\left[\mathrm{Cd}^{2+}\right]_{\text {initial }}-\left[\mathrm{Cd}^{2+}\right]_{\mathrm{eq}}}{\left[\mathrm{Cd}^{2+}\right]_{\text {initial }}}
$$

From the calculation result, for example, $\alpha$ at equilibrium of a $1 \mathrm{mM}\left[\mathrm{G} 2-\mathrm{OH}+4 \mathrm{Cd}^{2+}\right]$ $\left([\mathrm{G} 2-\mathrm{OH}]_{\text {initial }}=1 \mathrm{mM},\left[\mathrm{Cd}^{2+}\right]_{\text {initial }}=4 \mathrm{mM}\right)$ solution was estimated to be $70 \%$.

\section{Reference}

[1] A.B. Nepomnyashchii, M.A. Alpuche-Aviles, S.L. Pan, D.P. Zhan, F.R.F. Fan, A.J. Bard, Cyclic voltammetry studies of $\mathrm{Cd} 2+$ and $\mathrm{Zn} 2+$ complexation with hydroxyl-terminated polyamidoamine generation 2 dendrimer at a mercury microelectrode, J. Electroanal. Chem. 621 (2008) 286-296. 


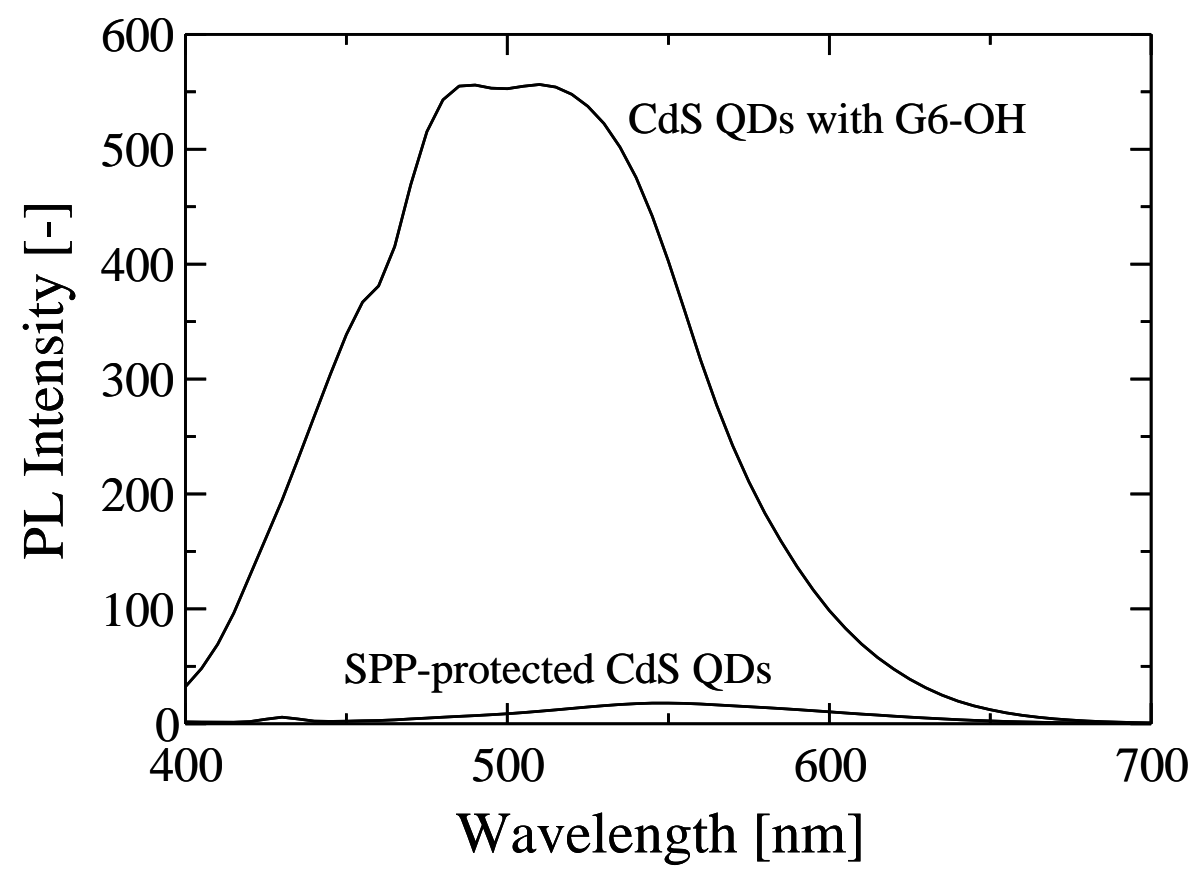

Figure S1. Comparison of PL intensity between CdS QDs with G6-OH PAMAM dendrimers and those with the SPP-protected dendrimers. The suspensions were prepared at room temperature. The concentrations of G6-OH and SPP were set to be 10 and $500 \mu \mathrm{M}$, respectively.

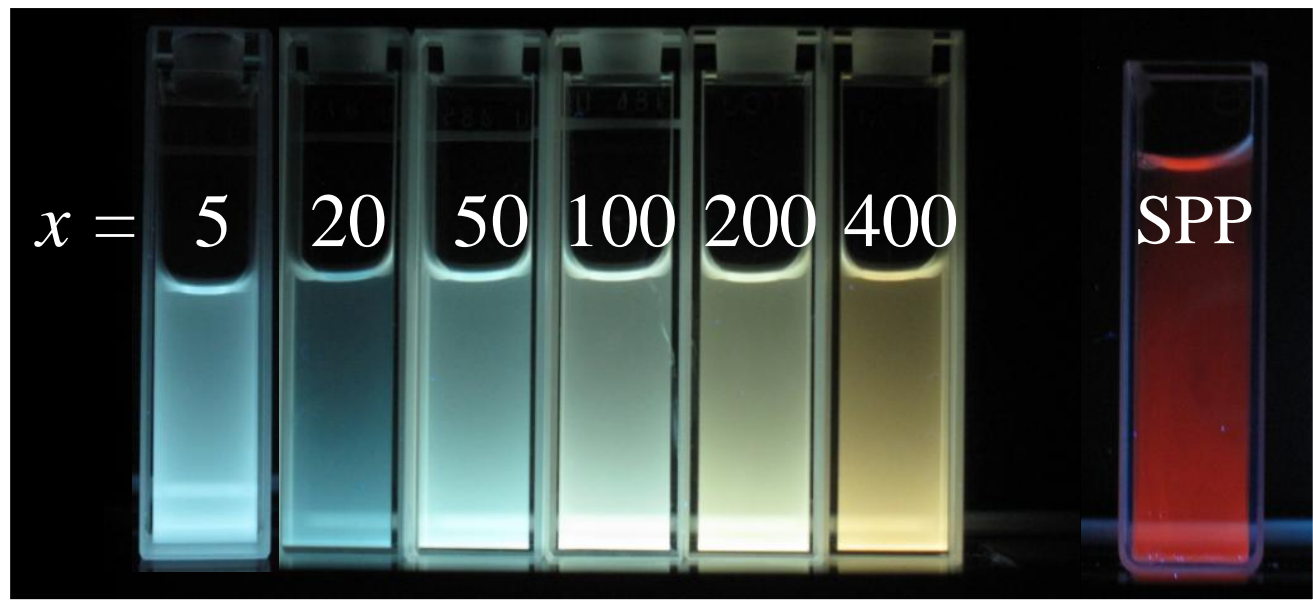

Figure S2. PL images of CdS QDs taken with a digital camera (Canon) within G6-OH dendrimers for various values of $x$ illuminated with a UV lamp $\left(\lambda_{\mathrm{ex}}=356 \mathrm{~nm}\right)$ in a dark room. 


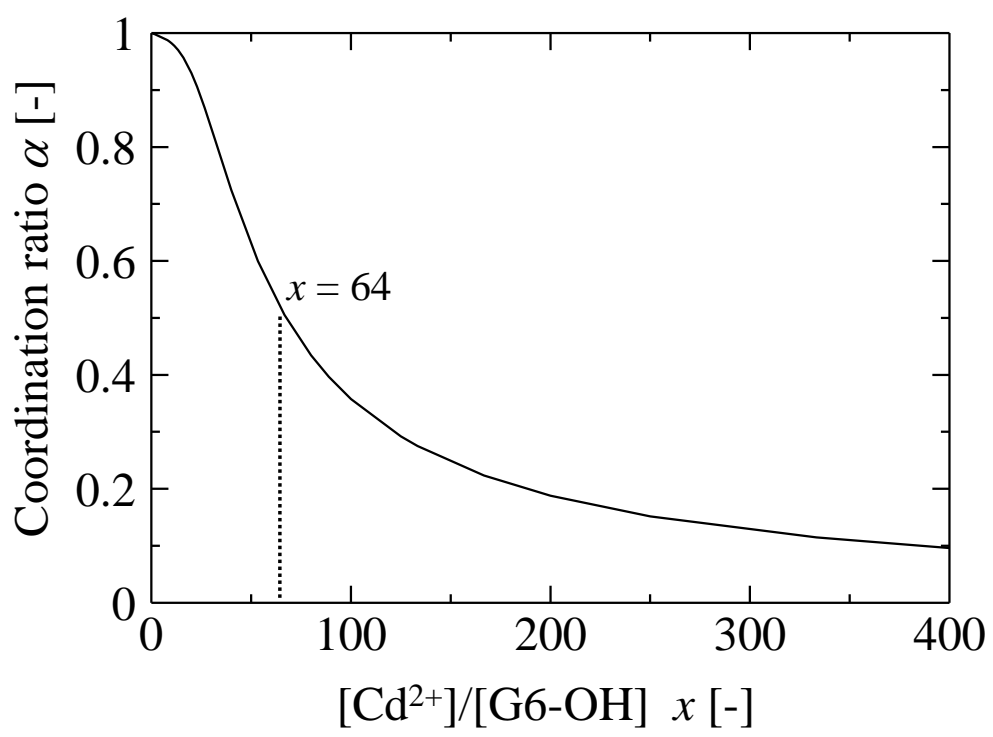

Figure S3. Coordination ratio of $\left[\mathrm{G} 6-\mathrm{OH}+x \mathrm{Cd}^{2+}\right]\left(\left[\mathrm{Cd}^{2+}\right]_{\text {initial }}=0.5 \mathrm{mM}\right)$ solutions.

The values were estimated according to "Supporting information: Calculation of $\mathrm{Cd}^{2+}$ coordination ratio at equilibrium." The concentrations of G6-OH were converted to those of $\mathrm{G} 2-\mathrm{OH}$ by the following equation: $[\mathrm{G} 6-\mathrm{OH}]=16 \times[\mathrm{G} 2-\mathrm{OH}]$.

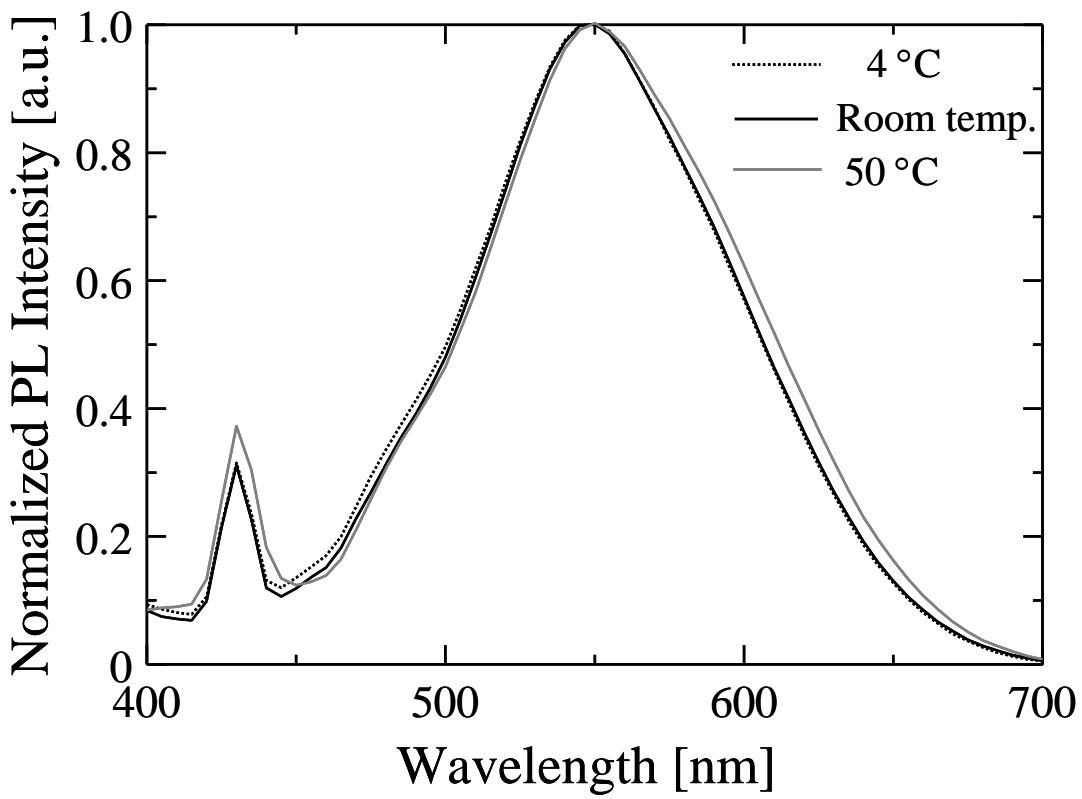

Figure S4. PL spectra of SPP-protected CdS QDs at various temperatures $\left(\lambda_{\mathrm{ex}}=374 \mathrm{~nm}\right)$. 